\title{
Horizontal Equity or Gatekeeping? Fiscal Effects on Eligibility Assessments for Long-term Care Insurance Programs in Japan
}

\author{
Masayoshi Hayashi ${ }^{\mathrm{a}^{*}}$, Haruka Kazama ${ }^{\mathrm{b}}$ \\ ${ }^{a}$ School of Public and International Policy and Graduate School of Economics, Hitotsubashi University \\ ${ }^{b}$ Mizuho Research Institute, Tokyo, Japan.
}

\begin{abstract}
This paper considers the effects of municipal fiscal climates on eligibility assessments in the Japanese system of long-term care insurance (LTCI). We find that municipalities with more stringent fiscal climates tend to reject more applications for LTCI benefits, almost certainly in the hope of containing benefit expenditures. This would not be a serious problem if financial assistance from the upper levels of government counteracted the adverse effect. However, we also find that the effects of the assistance are almost negligible, despite layers of intergovernmental subsidies for municipal LTCI expenditures. In other words, horizontal equity in Japanese longterm care insurance is compromised for the sake of gatekeeping.
\end{abstract}

JEL Classification: $\mathrm{H} 73, \mathrm{H} 75, \mathrm{H} 77, \mathrm{I} 18, \mathrm{I} 38$

Keywords: long-term care insurance, gatekeeping, horizontal equity

\section{Introduction}

In developed countries, the frail elderly are publicly provided with long-term care (LTC) services. While there is evidence that older people are healthier than just a few decades ago, there are widespread concerns that rapidly aging populations will entail significantly higher LTC expenditures, simply because the elderly have higher demands

* Corresponding author: School of Public and International Policy and Graduate School of Economics, Hitotsubashi University, Naka 2-1, Kunitachi, Tokyo, Japan 186-8063;. Email: hayashim@econ.hit-u.ac.jp. Tel: +81-42-580-8593. We gratefully acknowledge comments made by an anonymous referee, Michihito Ando, Shun-ichiro Bessho, Yasushi Iwamoto, Haruko Noguchi, Akihide Hirashima, Namiko Numao, Pierre Pestieau, Eiji Tajika and seminar participants at the City University of Hong Kong, Hitotsubashi University, Kyushu University, the Ministry of Internal Affairs and Communications and Tohoku University. We are also grateful to the Local Public Finance Coordination Division of the Ministry of Internal Affairs and Communications for helping us obtain data on the Adjustment Subsidy. The usual caveat applies. 
for ambulatory, inpatient, and chronic care. The issue is particularly pressing for Japan where the proportion of the elderly (those aged 65 years and over) in the populationafter tripling from 7 percent in 1970 to 20 percent in 2005 - is expected to be as high as 30 percent by 2030 . To address the problem, Long-term Care Insurance (LTCI) was introduced to cover those aged 65 years and over (Category I) and those between the ages of 40 and 64 years (Category II).

Municipalities manage their LTCI programs by setting up separate budgets. However, even before the introduction of the system in 2000, municipalities (cities, towns, and villages $)^{1}$ were responsible for both health insurance and social services for the retired and elderly; thus, they effectively administered long-term care (LTC) programs. The LTCI was then introduced to integrate this locally segmented system of health, medical, and welfare services to provide standardized benefits in every municipality across the country.

In the LTCI system, national law requires municipalities to set premiums for Category I subscribers, based on forecasts made for the three-year "program management period". Specifically, given the fixed shares of inter- and intragovernmental transfers, the premiums are set to balance the revenues and expenditures forecast for the period. While the national government sets minimum standards for LTCI benefits, municipalities are allowed to provide benefits over and above these standards. The premiums would then vary to the extent that municipalities provide any extra benefits, which is a natural, and possibly a desirable, thing to expect. In fact, this local determination of Category I premiums is thought to contribute to containing LTCI expenditures against the rapid pace of aging. Indeed, this explicit linkage between the benefits received and the premiums paid at the local level is claimed to be an important innovation (Campbell and Ikegami, 2000, Mitchell et al., 2004). ${ }^{2}$

However, premiums could also vary to the extent that there are disparities in needs and revenue capacities among municipalities. In the LTCI system, municipalities are expected to follow a set of identical standards so that uniform benefit applicability

\footnotetext{
${ }^{1}$ The Japanese local administration system consists of two levels of government: prefectures and municipalities (cities, towns and villages, plus Tokyo Metropolitan special districts). Municipalities, as the first tier, provide a wide range of public and personal services that are relevant to everyday life. In addition to social services and assistance, they include education, public health, policing, fire protection, water and sewage, and infrastructure. Prefectures, as the second tier, spatially include municipalities and function as a liaison between municipalities and the central government. They provide services whose benefits spill over municipal boundaries and those that require uniform standards across municipalities in their jurisdictions. They also conduct projects that are too large to be undertaken by municipalities, and when required, they offer assistance to municipalities. There are 47 prefectures (Tokyo-to, Hokkai-do, Osaka-fu, Kyoto-fu and 43 kens) that in aggregate are referred to in Japanese by the combined term, to-do-fu-ken. As of April 1, 2008, municipalities numbered 783 cities, 809 towns, 193 villages, and 23 special districts. As the national capital, Tokyo contains the 23 special districts, in addition to regular cities, towns, and villages. While it functions as a prefecture for regular municipalities, Tokyo also provides specific types of municipal services (e.g., police, fire protection, water supply, and sewage) for residents in the special districts that take on residual municipal services. Cities are further divided into 17 designated cities, 39 core cities, 43 special cities, and other regular cities, according to the administrative powers transferred from prefectures by the central government.

${ }^{2}$ The LTCI was also intended to reduce: (1) the burden of home care of the elderly, borne traditionally by women and (2) "social hospitalization", where elderly people were hospitalized simply because of a lack of viable long-term care services elsewhere.
} 
is maintained across the country. Uniform benefit standards, however, require redistributing funds among localities in the face of uneven revenue capacities and long-term care needs (Muiser and Carrin, 2007). In fact, there are large variations in Category I premiums: the highest premium $(6,100$ yen) is more than three times larger than the lowest (2,200 yen) for 2006-08 (Board of Audit, 2006). ${ }^{3}$ Given that only a small number of municipalities provide additional benefits (i.e., 106 from 1,681 municipalities in FY2005), any disparities are plausibly the result of differences in needs and capacities, rather than any extra benefits that municipalities choose to provide. If premiums differ despite benefits being uniform across the nation, then horizontal equity is compromised.

There may be yet another concern for horizontal equity. Municipalities also assess the needs of LTCI applicants and certify whether or not they are eligible for any benefit. Officially, municipalities are supposed to follow identical national standards, but they may use implicit local discretions not captured by the guidelines. For example, when the application of uniform standards fails to support applicants at the margin of eligibility, municipalities may want to help them if their budget capacity allows. Likewise, when faced with a stringent budget climate, they may tend to reject applications more often than otherwise to help constrain expenditure. The eligibility assessment could thus function as a gatekeeper and constitute a powerful containment mechanism against increasing LTCI benefits.

In fact, this is the only instrument with which municipalities can contain expenditures on a short-term basis, as municipalities are not permitted to change premiums for the three years of the management period or to reduce LTCI benefits below the minimum standards set by the national government. Indeed, the eligibility ratio among municipalities - the proportion of the eligible among those aged 65 years and over - ranges between 30.2 percent and 8.2 percent. While we may attribute at least some of these regional disparities to differences in long-term care needs, arbitrary applications of the eligibility criteria could be a major culprit (Board of Audit, 2006).

If the local discretions are operative, eligibility assessments could be affected by the fiscal status of municipalities, despite the official claim that assessments are fair and uniform throughout the nation. Then, given the large fiscal disparities among municipalities in Japan, the identically needy may become eligible in one location and not in another. It is thus important to establish empirically whether municipal fiscal climates affect the assessments for LTCI eligibility. Despite its importance, however, only a few studies have empirically evaluated this issue. Shimizutani and Inakura (2006) show that deficits in LTCI accounts tend to reduce the number of eligibility certifications. However, Ando (2007) argues otherwise by showing that the impact of the deficits is statistically insignificant and additionally demonstrates that higher premiums discourage municipalities from accepting more applications. The findings of these

\footnotetext{
${ }^{3}$ The figures are in terms of a standard monthly rate. In fact, the premium follows a progressive schedule, expressed as a multiple of the standard monthly rate.
} 
studies, however, conflict with each other and, as is usually the case with seminal work, have several issues to be refined and additionally explored. ${ }^{4}$

The current study aims to offer new and more reliable estimates for fiscal effects on LTCI eligibility assessments. Our study especially distinguishes itself from previous studies on the following counts. First, we consider the effects of financial assistance from the upper levels of government. We take advantage of two sources of variations to identify these effects. The first is the Adjustment Subsidy (AS) disbursed directly from the national budget to municipal LTCI budgets. Its matching rates, decreasing in fiscal capacities and increasing in LTC needs, are exogenous to municipalities and differentiated among municipalities. The second is the Local Allocation Tax (LAT), a general-purpose grant given to local governments from the national government. Because municipalities finance 12.5 percent of LTCI benefits from their general accounts, an increase in benefits causes an expenditure increase in the general accounts. The LAT disbursements cover this increase, thereby constituting an additional subsidy for LTCI benefits in LAT-receiving municipalities.

Secondly, we pay more attention to the endogeneity problems caused by the data structure utilized in LTCI studies. Because the LTCI started in 2000 with the municipalities as its insurers, the relevant data consist of a small number of annual observations $(T)$ spread over a large number of cross-section units $(N)$. Accordingly, as we use a large- $N$ panel to examine the fiscal effect on eligibility assessment, large $N$ asymptotics are more appropriate than large $T$ asymptotics for our study. While the weak exogeneity is not sufficient for consistent estimation with large $N$ panels, this issue is not fully explored in previous work. We then delineate specific issues stemming from large $N$ asymptotics that involve: (1) first-differenced variables, (2) relations among fiscal variables that have lagged feedbacks from the eligibility ratio, and (3) dynamic dependence of the dependent variable..$^{5}$ As shown below, carefully allowing for these factors yields different results for some of the more important fiscal variables.

To anticipate our findings, the effects of the subsidies from the upper levels of government are found to be almost negligible and statistically insignificant, while the variables that proxy for stringent fiscal climates and premium levels are found to reduce the eligibility ratio significantly. If the fiscal transfers encouraged municipalities to increase the eligibility ratio, the adverse effects (if any) of stringent fiscal climates would be mitigated. However, our result shows otherwise and implies that horizontal equity is compromised in favor of gatekeeping in the Japanese system of LTCI.

In what follows, we first outline the Japanese LTCI system in section 2 to provide the reader with some background information that helps them to grasp our empirical

\footnotetext{
${ }^{4}$ For example, the following issues are enumerated for Shimizutani and Inakura (2006). First, the fiscal variable, which is supposed to measure fiscal climates in municipal LTC accounts, is aggregated at the prefectural level because of data unavailability. Frankly, this makes the interpretation of the results quite difficult. Secondly, because only a single fiscal variable is considered for a single estimation model, the different effects of different fiscal variables (which may include the level of premiums, the degree of equalizing transfers and deficit status) are not identified. If these missing variables were correlated with the variables included in the model, it would surely produce problems with endogeneity. Thirdly, the endogeneity due to simultaneity between the differenced eligibility ratio and differenced fiscal variable is handled incorrectly by lagging the latter.
}

${ }^{5}$ For a technical argument that involves large $N$ asymptotics with panel data, see Wooldridge (2002). 
exercise. In section 3, we set up an empirical model that examines the fiscal effects on the eligibility assessments. After presenting the results in Section 4, we conclude our discussion in Section 5.

\section{Long-term Care Insurance in Japan}

\subsection{Benefits}

The Long-term Care Insurance (LTCI) in Japan covers persons aged 65 years and over (Category I) and those aged between 40 and 64 years (Category II). To be eligible for LTCI benefits, prospective recipients apply to have their needs assessed by their municipality of residence. The assessment process is as follows. First, upon application, an examiner visits and interviews the applicant and checks various items on his/her physical and mental status. Secondly, the checklist filled in by the examiner is compiled into a computer program that automatically assesses the applicant's needs.

Thirdly, a committee of local experts reviews the computer results, along with the written information obtained from the first-stage examiner and the applicant's doctor, and alters the result if necessary. In all of these assessing stages, only the applicant's physical and mental condition is supposed to be considered. Personal financial status and other factors are not taken into account. Those who are eligible are then classified into several stages according to the severity of their needs. There were six stages of needs (SR (Support Required) and CR (Care Required) 1-5) from the start of the LTCI in 2000 until 2005. Since 2006, however, the SR stage has been subdivided into SR1 and SR2, and there are now seven stages in total. The results are notified within 30 days of application. If dissatisfied with the decision, applicants can appeal to an agency at the prefectural level and ultimately to the courts. Eligibility is reevaluated every six months.

When certified as eligible, subscribers are entitled to "purchase" long-term care services from their provider of choice, in exchange for copayments that amount to 10 percent of the actual service expense (i.e., the LTCI benefit amounts to 90 percent of the expense). Thus, benefits are in kind, not in cash. Providers can be either public or private, though private providers have to be publicly certified by the prefecture.

The eligible can receive benefits up to the ceiling set by the national government. The ceilings increase in seven stages according to the severity of individual needs, from 49,700 yen (about US\$450) to 358,300 yen (about US\$3,260) per month. Because municipalities can provide extra benefits out of their own budget, the ceiling set by the national government constitutes the minimum standard guaranteed across the nation. A variety of long-term care services are now covered by LTCI benefits. However, the LTCI does not cover some services. For example, it does not cover meal expenses for those who are hospitalized or institutionalized. Also, the benefits are limited to some specific age-related diseases for Category II subscribers. In addition, persons classified in the two lowest stages (SR1 and SR2) are not eligible for institutional care services. Of course, those who are eligible, if they desire, can purchase additional services out of their own pocket, beyond what the public sector provides. 


\subsection{Financing}

Municipalities set up a special account for their LTCI programs, and set annual budgets that they are required to balance on a three-year basis. The three-year period for budget planning is called the "program management period (jigyo un-ei kikan)". When drawing up budgets, municipalities forecast local LTCI expenditures for the entire three years. Because prices are set by the national government and are effectively held constant, the issue boils down to the volume of services demanded. Forecasting the volume of institutional care is straightforward because it is capped by the capacity of related facilities. Estimating the volume of home care is rather more complicated, however, because it involves forecasting: (1) the number of people eligible, (2) the number of applications for LTCI certification, and (3) the extent to which those who are certified as eligible utilize their entitlements.

After expenditure forecasts are obtained, revenues are considered. The first part of LTCI benefits is financed by taxes. ${ }^{6}$ First, the central government covers 20 percent of the benefit expenditures through the "Long-term Care Benefits Subsidy (LTC-BS)". Secondly, the LTC-BS is accompanied by an additional grant called the "Adjustment Subsidy (AS)". The AS allocates central funds that in aggregate equal 5 percent of all benefits. The AS grants are distributed with matching rates that depend on the percentage of those aged 75 years and over and the average income of those aged 65 and over. While the minimum value for the matching rates is zero, the maximum differs from year to year. ${ }^{7}$ Thirdly, prefectures, through the Cost-sharing Subsidy (CSS), transfer their funds to cover 12.5 percent of municipal benefits in their jurisdictions. Finally, another 12.5 percent is financed by intramunicipal transfers from the general account to the LTCI account within a municipality. Note that these tax-financed shares are all based on actual expenditures rather than planned estimates. Nevertheless, actual expenditures exclude extra benefits that municipalities provide independently over and above the standards set by the national government.

The contributions from the municipal general accounts to the LTCI special account are counted in the "standard fiscal demand" used for the calculation for the disbursements of the Local Allocation Tax (LAT), the system of general-purpose fiscal transfers to local governments in Japan. Because the intramunicipal contributions to the LTCI special account are proportional (12.5 percent) to actual LTCI benefits payments, an increase in the benefits is partially compensated for by an increase in the LAT disbursements calculated as the difference between "standard fiscal demand" and "standard fiscal revenue". In other words, LAT recipients can expect an increase in their LAT disbursements when their LTCI benefits increase. In other words, LAT-receiving municipalities are indirectly subsidized through the LAT.

\footnotetext{
${ }^{6}$ From FY2003, 3\% of the total benefit payment is allocated for regional support programs. Regional support programs are then grouped into: (i) prevention service programs, (ii) comprehensive support programs and (iii) independent programs. The cost sharing for the prevention service program is identical to that described in the text. The other two programs have no shares for Category II premiums, and the tax-financed part is expanded to fill the void: the national, prefectural, and municipal shares are now $40.5 \%, 20.25 \%$ and $20.25 \%$, respectively.
}

${ }^{7}$ For example, the percentages were 12.03 in 2003, 11.08 in 2004, and 11.65 in 2005. 
The second part of the LTCI benefits is financed from two types of premium. The premiums paid by those aged between 40 and 64 years (Category II premiums) ${ }^{8}$ are nationally pooled at the Social Insurance Medical Fee Payment Fund (SIMFPF) and then allocated as the Fee Payment Fund Grants (FPFG) to uniformly cover 31 percent of LTCI benefits. Therefore, this grant favors municipalities where Category II shares are less than the average, and so it works as an equalizing device.

The remainder, whose proportion varies depending on the size of the AS matching rate, is financed from the premiums paid by municipal residents aged 65 years and over (Category I subscribers). The premium schedule is progressive and consists of multiples of a standard premium rate with multiplying coefficients. The national guideline sets out six income brackets and applies a set of multiplying coefficients $(0.50$, $0.50,0.75,1.00,1.25$, and 1.50) with larger values for the upper brackets. ${ }^{9}$ As shown, the standard premium applies to the fourth bracket.

The standard premium rates are set to balance the forecasted budgets on a three-year basis. The premiums are held fixed during the entire three-year period. Because Category I premiums are based on forecasts, annual realized budgets do not usually balance. When surpluses occur, they are saved in the Long-term Care Benefits Funds (LTC-BF) against future deficits. However, if deficits are severe enough to exhaust the LTC-BF, additional assistance is required as municipalities are not permitted to finance deficits with transfers from their general accounts. In such a case, loans are made from the Fiscal Stabilization Funds (FSF). ${ }^{10}$ The loans borrowed in a given three-year period are repaid in the next three-year period with funds financed from Category I premiums. Receiving loans thus implies a future hike in Category I premiums. ${ }^{11}$

\subsection{Gatekeeping}

As explained, Category I premiums are set to balance planned budgets on a threeyear basis and are held constant for three years. In addition, if FSF loans are borrowed because of unexpected deficits, loan payments are financed from an increase in Category I premiums in the next three-year period. One argument is that this linkage of costs and benefits at the local level provides an incentive for municipalities to contain demand expansion. This is claimed to be an important policy innovation (Campbell and Ikegami, 2000).

\footnotetext{
${ }^{8}$ The Category II premiums are collected as a surcharge on public health insurance premiums. In fact, this is a payroll tax and is split equally between employers and employees. The rate is $0.95 \%$ of salary for Government-managed Health Insurance and $0.88 \%$ for Association-managed Health Insurance.

${ }^{9}$ Some municipalities subdivide brackets higher than the fourth bracket and apply a complex premium schedule to those they consider well off.

${ }^{10}$ Prefectures manage the FSF and cover municipalities within their jurisdictions. The central, prefectural, and municipal governments share equally the costs for the FSF. The contributions by municipalities to the FSF are financed from their Category I premiums.

${ }^{11}$ In addition, grants from the FSF in the last year of the three-year period in a management period compensate for half of the accumulated differences between the forecast premium revenues and realized premium revenues. This effectively works likes an ex post subsidy supplementing fiscally weak municipalities.
} 
However, the policy instruments formally available to municipalities are limited and only indirectly contain expanding long-term care (LTC) demands. First, municipalities are not permitted to reduce LTCI benefits below the minimum standard set by the national government. In fact, more than 90 percent of all municipalities operate on the minimum standard and cannot reduce the benefit level to deal with expanding LTC demands. Secondly, because the provision of long-term care services involves the private sector, the private suppliers may induce some proportion of the demand. The suppliers may be tempted to exploit information asymmetries and persuade their clients to purchase services not actually needed. Thirdly, while increasing needs may be tamed by health promotion activities, it may take time to realize their effects. There are indeed programs that aim to promote health among the elderly: so-called "Prevention Service Programs". However, short-term fluctuations in LTCI benefits are difficult to control with such measures.

The LTCI benefits may also be controlled by adjusting the eligibility criteria. In fact, eligibility assessment is the only short-term instrument for municipalities to contain LTCI benefits, because the national government fixes the minimum benefits uniformly. Therefore, despite the claim by the central government that fair and uniform assessment is implemented throughout the nation, municipalities may take advantage of implicit local discretions that are not captured by the national guidelines. For instance, municipalities with stringent budgets may tend to reject applications more often than otherwise to contain their benefit expenditures. In addition, as far as their budget capacity allows, municipalities may circumvent the national guidelines to help applicants with needs at the margin. In either case, the assessments may be affected by municipal fiscal climates.

Eligibility assessments may also be affected by the service capacities of municipalities, which should typically be the case for institutional care. The available institutional care reflects the capacities of LTCI facilities. In many municipalities, the aggregate capacity of LTCI facilities is in fact well below aggregate eligible demand. Therefore, when municipalities expect new eligible applications, they may simply turn them down.

The above argument implies that the expert committee that finalizes LTCI eligibility may not be an independent decision-making unit as officially claimed. The committee is composed of medical and welfare specialists whose professional assessments are supposed to be neutral and independent of municipal fiscal climates. However, municipal governments do have leeway in arranging and appointing the chair and members of these committees. In addition, the first-stage examiners, who check the applicants and prepare documents for certification, are contracted to municipal governments or, in some cases, are local officials themselves. Furthermore, even if municipalities do not meddle with the assessment process, there may be some ethos among the committee members that helps contain the expansion of benefits. For instance, the status of the LTCI budget would be highly public information among those involved in the assessment process. 


\section{Empirical Model}

\subsection{The Baseline Model}

We set up an empirical model for gatekeeping behavior of municipalities that adjusts the number of the LTCI eligibility certifications in response to their fiscal conditions. In the ensuing analysis, we utilize a panel of municipal data from 2004 to 2005, which falls within the program management period of $2003-2005 .{ }^{12}$ We use the eligibility ratio $Y_{i t}$ to represent gatekeeping behavior. The ratio $Y_{i t}$ is given as the proportion of those who are eligible $\left(E_{i t}\right)$ for LTCI benefits among those who are aged 65 years and over $\left(S_{i t}\right)$ in municipality $i$ in year $t\left(Y_{i t} \equiv E_{i t} / S_{i t}\right)$.

The following points are worth mentioning. First, we are in fact interested in the "take-up rate" $\left(E_{i t} / E_{i t}{ }^{*}\right)$, the proportion of those who are actually certified eligible $\left(E_{i t}\right)$ among those who should have been certified eligible $\left(E_{i t}{ }^{*}\right)$. In other words, $E_{i t}{ }^{*}$ represents the true volume of long-term care needs, or the number of those who would be certified as eligible if assessments were properly made by strictly following a uniform rule. Of course, as $E_{i t}{ }^{*}$ is not observable, we cannot directly use the take-up rate as the dependent variable. However, note that the eligibility ratio is decomposed as:

$$
Y_{i t} \equiv \frac{E_{i t}}{S_{i t}}=\frac{E_{i t}}{E_{i t}^{*}} \cdot \frac{E_{i t}^{*}}{S_{i t}}
$$

This shows that the eligibility ratio is influenced by two factors: (a) the take-up rate $\left(E_{i t} / E_{i t}{ }^{*}\right)$ and (b) the proportion of the truly eligible among the insured $\left(E_{i t}{ }^{*} / S_{i t}\right)$. Although $E_{i t}{ }^{*} / S_{i t}$ is unobservable with $E_{i t}{ }^{*}$ being unobservable, we note that $E_{i t}{ }^{*} / S_{i t}$ does reflect longterm care needs. We could then net the variations in $E_{i t}{ }^{*} / S_{i t}$ out of those in $Y_{i t}$ by including a set of dependent variables that proxy for the long-term care needs. Our model thus includes, along with the set of fiscal variables $\left\{x_{1, i t}, x_{2, i t}, \ldots, x_{K, i t}\right\}$ that may influence the take-up rate $E_{i t} / E_{i t}{ }^{*}$, a set of variables $\left\{z_{1, i t}, z_{2, i t}, \ldots, z_{L, i t}\right\}$ that affect the proportion of the truly eligible among the insured $E_{i t}{ }^{*} / S_{i t}$ or the long-term care needs.

Secondly, we model gatekeeping behavior with a linear regression model that has an additive error $u_{i t}$, which in principle takes on any value between $-\infty$ and $+\infty$. Because dependent variable $Y_{i t}$ only takes on values between 0 and 1, this setup requires either the logit-transformation of $Y_{i t}$ so that the transformed value takes on values between $-\infty$ and $+\infty$, or a special assumption on the distribution of error term $u_{i t}$, which would lead us to estimate the model with maximum likelihood methods. We select the first option and transform the dependent variable as:

$$
y_{i t} \equiv \ln \left(\frac{Y_{i t}}{1-Y_{i t}}\right)
$$

\footnotetext{
${ }^{12}$ Some key variables are unavailable on a municipal basis prior to 2004. The most recent data available are for 2005 .
} 
We thus specify the regression model as:

$$
y_{i t}=\alpha_{0}+\alpha \cdot t+\sum_{k=1}^{K} \beta_{k} \cdot x_{k, i t}+\sum_{l=1}^{L} \gamma_{l} \cdot z_{l, i t}+\rho \cdot y_{i t-1}+c_{i}+u_{i t} \text {, }
$$

where $\alpha_{0}, \alpha, \beta_{k}$, and $\gamma_{l}$ are parameters to be estimated, $c_{i}$ is unobserved heterogeneity and $u_{i t}$ is idiosyncratic error. Note that $\alpha$, the coefficient on a linear time trend $t$, is a drift that shows average changes in $y_{i t}$ that are not explained by the explanatory variables. The partial adjustment model motivates the lagged dependent variable on the righthand side of the equation. We will also estimate the model without the lagged dependent variable to observe the effects of the dynamic specification.

\subsection{Fiscal Variables}

\subsubsection{Stringent Fiscal Climates}

We express fiscal difficulties in terms of Category I premiums and the loans from the Fiscal Stabilization Funds (FSF). Because Category I premiums are fixed during a program management period that spans three years, deficits could occur with poor budget forecasts. As discussed, if the deficits are severe enough to receive the FSF loans in a given program period, municipalities are expected to repay them by increasing Category I premiums in the next program period. Municipalities may wish to avoid such hikes in premiums, and their aversion will be greater if their current premiums are already high. If so, a higher level of Category I premium may encourage municipalities to reduce the eligibility ratio.

We take the natural logarithm of the standard rate $P_{i}, p_{i} \equiv \ln P_{i}$. The premium rates were fixed for the period we consider (2004-2005). Our assumption is that the effect of the premiums would be larger as the three-year period approaches its end. The aversion against yet higher premiums may make municipalities reduce the eligibility ratio, but such adjustments would plausibly take place gradually. Because what matters is what happens in the whole three-year period (and what is expected in the next three-year period), municipalities would wait and see what happens at the beginning of the period. As time passes, they would then come to realize the whole picture of the fiscal situation in this three-year period and start to accelerate their adjustments. We thus interact the log of premiums $p_{i}$ with a linear time trend $t$, i.e. $x_{1, i t}=t \cdot p_{i}$ so that we can let the premium level affect annual changes in $y_{i t}$.

Aversion to future hikes in premiums will also be greater for municipalities that have accumulated loans from the FSF. All other things being equal, the larger the amount of the loan accumulated in a given program period, the higher the premiums expected in the next program period. In other words, FSF loans accumulated in a given program period imply future hikes in Category I premiums. Municipalities with more FSF loans would then want to contain LTCI expenditures more eagerly, because their expansion places further upward pressure on premiums. We express the size of FSF loans $\left(B_{i t}\right)$ accumulated in a given program period in terms of its ratio $\left(b_{i t}\right)$ to the amount 
of Category I premium revenues $\left(R_{i t}\right)$ collected in the same period. Because our data fall within a single program management period, 2003-2005, this is given as:

$$
x_{2, i t}=b_{i t} \equiv \frac{\sum_{s=2003}^{t-1} B_{i s}}{\sum_{s=2003}^{t-1} R_{i s}}
$$

Note that $b_{i t}$ in year $t$ depends on variables in years $s<t$, and $b_{i 2003}=0$ for all $i$.

\subsubsection{Subsidies from Upper Levels of Government}

While stringent fiscal climates may discourage municipalities from certifying eligibility, subsidies from upper levels of government, which mitigate fiscal stringency, may counteract these adjustments. We have already discussed how grants through the Adjustment Subsidy (AS) are allocated among municipalities with different matching rates over and above the fixed expenditure shares of the central LTC-BS and the prefectural CSS. Because the matching rates for the AS grants vary across municipalities, we can take advantage of this to identify the effects of subsidies on the eligibility ratio. The subsidy rates from the upper levels of government are given as:

$$
x_{3}=g_{i t} \equiv .20+.125+a_{i t}
$$

where $a_{i t}$ is the AS matching rate.

We have also discussed how LAT recipients are considered to be receiving additional subsidies, because the proportion of the LTCI benefits financed from municipal general budgets is compensated for by the LAT disbursements. We thus conjecture that the receipt of LAT may affect the eligibility ratio. We express this using a binary variable:

$$
x_{4, i t}=d_{i t} \equiv 1\{i \text { is a LAT recipient }\}
$$

which takes on a value of 1 if a municipality is a LAT recipient and 0 otherwise.

\subsubsection{Service Capacity}

We have tentatively argued that when more applicants become eligible than the capacity of the existing LTCI facilities allow, municipalities may accept fewer applications to reduce the degree of institutional care rationing. We express the degree of the undercapacity of LTCI facilities in terms of the number of those aged 65 years and over $\left(S_{i t}\right)$ per number of beds available $\left(Q_{i t}\right)$ in designated LTCI facilities. Because these facilities are supervised by the prefectures and are open to the needy beyond municipal borders, we aggregate data on LTCI facilities at the prefectural level:

$$
x_{5, i t}=q_{i t} \equiv \ln \left(\frac{\sum_{j \in i \text { 's prefecture }} S_{j t}}{\sum_{j \in i^{\prime} \text { s prefecture }} Q_{j t}}\right)
$$


The supply of home care services may also be rationed by the stock of home care service providers. Given the socioeconomic diversity of municipalities, it is not difficult to imagine that the market sizes for home care providers are substantially different. Market size may be proxied by the density of the elderly in the population or the population itself. However, because the area that a municipality covers is constant over time in our sample, and because both population and the elderly ratio are included as regressors as shown below, these effects are controlled for in our estimation without adding additional regressors.

\subsection{Control Variables and Unobserved Heterogeneity}

\subsubsection{Long-term Care Needs}

Recall that the eligibility ratio is decomposed into two factors, (1) the take-up rate $\left(E_{i l} / E_{i t}{ }^{*}\right)$ and (2) the proportion of the truly eligible among the insured $\left(E_{i t}{ }^{*} / S_{i t}\right)$. Because we are interested in the effect on the take-up rate, we control the variations in $E_{i t}{ }^{*} / S_{i t}$ by including the following variables. First, $E_{i t}{ }^{*} / S_{i t}$ would be most influenced by the degree of aging in municipalities as long-term care needs will increase as the population ages. We control this effect by including (a) the proportion of those aged 65 years and over $\left(S_{i t}\right)$ in the municipal population $\left(P_{o p}\right)$ and $(b)$ the proportion of those aged 75 years and over $\left(S_{i t}{ }^{75+}\right)$ among those aged 65 years and over $\left(S_{i t}\right)$.

Secondly, income level could also be important as persons with higher incomes may have greater capacity to pay attention to their health than those with lower incomes. The LTCI system categorizes those aged 65 years and over into six income brackets and documents how many fall in each bracket. Because the standard premium rate applies to those in the fourth bracket, we refer to brackets lower than the fourth bracket as "poor" and those in higher brackets as "rich". With the number of those who fall in the $j$-th bracket $S_{i t}^{j}$, the numbers for the "poor" and the "rich" are given as $S_{i t}{ }^{P} \equiv S_{i t}{ }^{1}+S_{i t}{ }^{2}+S_{i t}{ }^{3}$ and $S_{i t}^{R} \equiv S_{i t}^{5}+S_{i t}^{6}$ respectively. We use the ratio $\left(S_{i t}{ }^{P} / S_{i t}, S_{i t}{ }^{R} / S_{i t}\right)$ as a proxy for income factors.

The income factors could also affect the take-up rate $E_{i l} / E_{i t}{ }^{*}$, because they may also affect the number of applications $\left(E_{i t}\right)$, which evidently excludes those who do not apply. People may not apply if they do not expect appropriate services from the certified providers within the LTCI system. In particular, when the needy are rich enough and they find better services outside the system, they may not apply for LTCI benefits.

We use these ratios in natural logarithms: $z_{1, i t}=\ln \left(S_{i t} / P o p_{i t}\right), z_{2, i t}=\ln \left(S_{i t}^{75+} / S_{i t}\right)$, $z_{3, i t}=\ln \left(S_{i t}{ }^{P} / S_{i t}\right)$, and $z_{4, i t}=\ln \left(S_{i t}{ }^{R} / S_{i t}\right)$. Given that model (1) is linear in parameters, including these four variables along with either the $\log$ of total population $\left(\ln \left(\right.\right.$ Pop $\left.\left._{i t}\right)\right)$ or the $\log$ of the elderly population $\left(\ln \left(S_{i t}\right)\right)$ is effectively equivalent to regressing the natural logarithms of all of the variables in levels $\left(\ln \left(S_{i t}\right), \ln \left(P o p_{i t}\right), \ln \left(S_{i t}{ }^{75+}\right), \ln \left(S_{i t}{ }^{P}\right)\right.$, and $\left.\ln \left(S_{i t}^{R}\right)\right)$ with a different parameterization. The difference simply lies in the interpretation of the parameter estimates. We choose to include the log of population as an additional regressor: $z_{5, i t}=\ln \left(P o p_{i t}\right)$. 


\subsubsection{Unobserved Heterogeneity}

In addition to the level of income, several other factors may also affect the number of LTCI applications. For example, Endo and Yoshida (2001) argue that the demand for long-term care services depends on the family composition of the elderly. An analogous logic may apply to the number of the LTCI applications. The frail elderly may prefer care services provided by their family members to those provided by strangers (i.e., the LTCI service providers). If so, they may not apply if equivalent care services are available within their family, implying that family composition may affect the eligibility ratio.

While data on family are not obtainable, we could safely assume that family composition is stable for the period of our data span (i.e., two years). If so, this effect is controlled for by unobserved heterogeneity $c_{i}$ in (1). Plausibly, other unobservable factors influence the eligibility ratio but are also stable over time. The unobservable heterogeneity allows for any unobservables that are stable for the two years but different across municipalities.

\section{Estimation}

\subsection{Model for Estimation}

To allow for the unobserved heterogeneity, we can estimate a model in (a) levels with unobserved heterogeneity as (1), or (b) first differences without unobserved heterogeneity. We opt for the differenced model because the endogeneity problem is more straightforwardly handled (Wooldridge, 2002). With our data of annual observations for 1,120 municipalities spanning two years (2004 and 2005), the firstdifferenced version of model (1) is expressed as:

$$
\begin{aligned}
\Delta y_{i 2005}= & \alpha+\beta_{1} \cdot p_{i}+\beta_{2} \cdot \Delta b_{i 2005}+\beta_{3} \cdot \Delta g_{i 2005}+\beta_{4} \cdot \Delta d_{i 2005}+\beta_{5} \cdot \Delta q_{i 2005} \\
& +\sum_{l=1}^{5} \gamma_{l} \cdot \Delta z_{l, i 2005}+\rho \cdot \Delta y_{i 2004}+\varepsilon_{i 2005},
\end{aligned}
$$

where $\varepsilon_{i 2005} \equiv u_{i 2005}-u_{i 2004}$ is the error term. Note that with differencing, unobserved heterogeneity disappears and the data set reduces to a cross-section of differenced data that consists of 1,120 observations (i.e., $T=1, N=1,120$ ).

\subsection{Econometric Issues}

With our data structure explained, it is evident that large $N$ asymptotics are of course more appropriate than large $T$ asymptotics for the current analysis. With large $N$ asymptotics, consistent OLS estimation requires strict exogeneity of the error term, and 
endogeneity could stem from predetermined explanatory variables. In this regard, the following points are worth noting. First, the dynamic specification makes $\Delta y_{i 2004} \equiv y_{i 2004}$ $-y_{i 2003}$ and $\varepsilon_{i 2005} \equiv u_{i 2005}-u_{i 2004}$ correlated with each other, because $y_{i 2004}$ is affected by $u_{i 2004}$ through (1). A good instrument for $\Delta y_{i 2004}$ may be $\Delta y_{i 2003} \equiv y_{i 2003}-y_{i 2002}$, which is independent of $\varepsilon_{i 2005} \equiv u_{i 2005}-u_{i 2004}$ (assuming the $u_{i t}$ are serially independent) and should be highly correlated with $\Delta y_{i 2004} \equiv y_{i 2004}-y_{i 2003}$. Because $\Delta y_{i 2003} \equiv y_{i 2003}-y_{i 2002}$, we in fact use $y_{i 2003}$ and $y_{i 2002}$ as instruments. We also use lagged explanatory variables that are considered to be strictly exogenous in (1) as additional instruments (i.e., $g_{i 2004}, q_{i 2004}$, $\left.z_{1, i 2004}, z_{2, i 2004}, z_{3, i 2004}, z_{4, i 2004}, z_{5, i 2004}\right)$, because they evidently affect $y_{i 2004}$ and are independent of $u_{i 2004}$.

Secondly, the lagged feedbacks from $\Delta y_{i t}$ on the regressors cause yet another endogeneity. In our case, this is typically true of $b_{i t}$, the accumulated FSF loans normalized by the accumulated revenues. There are feedbacks from the eligibility ratio in the previous year to the accumulated FSF loans in the current year, because the FSF loans accumulate when revenues were surpassed by benefit expenditures in the past. Moreover, the benefits in the past were influenced by the eligibility ratio in the same period. This makes $\Delta b_{i 2005} \equiv b_{i 2005}-b_{i 2004}$ correlated with $\varepsilon_{i 2005} \equiv u_{i 2005}-u_{i 2004}$, because $u_{i 2004}$ affects $b_{i 2005}$ via $y_{i 2004}$. Again, once-lagged value $\Delta b_{i 2004}$ can be used as an instrument for $\Delta b_{i 2005}$ as $\Delta b_{i 2004} \equiv b_{i 2004}-b_{i 2003}$ is independent of $\varepsilon_{i 2005} \equiv u_{i 2005}-u_{i 2004}$ and should be correlated with $\Delta b_{i 2005}$. However, note that we are only allowed to use $b_{i 2004}$ because $b_{i 2003}=0$ with the three-year program management period starting at $t=2003$. Note that $b_{i 2005}$ should be highly correlated with factors that influence revenues and benefits for $t=2003-2004$. It is then straightforward to include as additional instruments the $\log$ of per elderly revenues $\left(r_{i t} \equiv \ln \left[\left(R_{i t}+A_{i t}\right) / S_{i t}\right]\right.$ where $R_{i t}$ is Category I premiums and $A_{i t}$ is the Adjustment Subsidy) for $t=2003-2004$, and the $\log$ of per elderly benefits $\left(m_{i t} \equiv \ln \left(M_{i t} / S_{i t}\right)\right.$ where $M_{i t}$ is total benefits) for $t=2003$, because by definition $r_{i 2003}, r_{i 2004}$ and $m_{i 2003}$ affect $\Delta b_{i 2005}$ but are independent of $\varepsilon_{i 2005}$. Because the FSF loans borrowed partly reflect the unexpected loss in revenues, we also consider premium collection rates $\left(R_{i t} / R_{i t}{ }^{*}\right)$ where $R_{i t}{ }^{*}$ is expected revenues. However, we use instead the log of missing rates defined as $h_{i t} \equiv \ln \left(1-R_{i t} / R_{i t}{ }^{*}\right)$ for $t$ $=2003-2004$.

Thirdly, neither lagged feedback nor contemporaneous simultaneity is caused by standard premiums $p_{i}$ or subsidy rates $g_{i t}$. Given the manner in which premiums are determined, their values are affected by eligibility ratios in the previous threeyear period (2000-2002). What matters in our estimation is a feedback that makes $\varepsilon_{i 2005} \equiv u_{i 2005}-u_{i 2004}$ and $p_{i}$ correlate, which is institutionally impossible because $p_{i}$ is held fixed for 2003-2005. In addition, the subsidy rates are all institutionally fixed and independent of either the eligibility ratio or the level of LTCI benefits.

Fourthly, we regard $\Delta d_{i 2005}$ as independent of $\varepsilon_{i 2005}$. At first glance, $d_{i t}$ may appear to be endogenous as a higher eligibility ratio implies higher benefit expenditures. This leads to an increase in LAT disbursements. While true, such changes in LAT grants (intensive margins) are different from changes in LAT recipient status (extensive margins). Changes in the eligibility ratio will affect the extensive margin only if 
municipalities cluster within a narrow bound around the threshold where standard fiscal demands and standard fiscal revenues are balanced. Because this is not the case in our data, and the LTCI expenditures only account for a tiny share of standard fiscal demand, we could safely assume that changes in recipient status are independent of changes in the eligibility ratio.

\subsection{Data and Estimation}

We obtain the parameters of the differenced model (2) as (a) OLS estimates (as a reference) and (b) IV estimates with an optimal weighting matrix (i.e., Hansen's univariate GMM estimator). The matrix of instruments comprises the above variables

$\left(y_{i 2003}, y_{i 2002}, g_{i 2004}, q_{i 2004}, z_{1, i 2004}, z_{2, i 2004}, z_{3, i 2004}, z_{4, i 2004}, z_{5, i 2004}, r_{i 2003}, r_{i 2004}, m_{i 2003}, h_{i 2003}, h_{i 2004}\right)$ and those variables regarded as strictly exogenous in the model $\left(p_{i}, \Delta g_{i 2005}, \Delta d_{i 2005}, \Delta\right.$ $\left.q_{i 2005}, \Delta z_{1, i 2005}, \Delta z_{2, i 2005}, \Delta z_{3, i 2005}, \Delta z_{4, i 2005}, \Delta z_{5, i 2005}\right)$. Just in case the error term $\varepsilon_{i 2005}$ exhibits an unknown heteroskedasticity pattern, we adjust the covariance matrix estimators for (a) and (of course) for (b). We also estimate a static version of (2), excluding $\Delta y_{i 2004}$ from the r.h.s. of the dynamic equation. When we estimate this model with instruments, we exclude from the set of instruments those that specifically account for this variable (i.e., $\left.y_{i 2003}, y_{i 2002}, g_{i 2004}, q_{i 2004}, z_{1, i 2004}, z_{2, i 2004}, z_{3, i 2004}, z_{4, \mathrm{i} 2004}, z_{5, i 2004}\right)$.

Table 1 summarizes the descriptive statistics (without logs or differencing) of the variables used for the estimation along with their sources. As shown, we utilize municipal data for the period from 2002 to 2005. During this period, the number of municipalities was drastically reduced from 3,218 (FY2002) to 2,395 (FY2005) because of a large number of municipal amalgamations (consolidations) actively driven by the national government. Given our estimation structure, we then exclude from our sample those municipalities amalgamated during the period. In addition, we also exclude a small number of municipalities that manage their LTCI programs jointly with other municipalities.

This reduces the sample size to 1,120 and makes our econometric inference conditional on the municipalities characterized as above. While this conditioning of the sample may make inference less straightforward, we argue that it would nonetheless effectively supplement and bolster our arguments. As we will see, the variables that surrogate stringent fiscal climates are found to reduce the eligibility ratio. Because there is additional empirical evidence that municipalities with lower fiscal capacity are more likely to amalgamate (e.g., Hirota, 2006) and the joint LTCI programs are run by municipalities with weak fiscal resources, we see that our results hold, even with a sample consisting of municipalities that may be considered to be endowed with stronger fiscal resources. 
Table 1. Sample Statistics

\begin{tabular}{|c|c|c|c|c|c|c|}
\hline & Year(s) & Mean & S.E. & Minimum & Maximum & Source \\
\hline \multirow{3}{*}{ Eligibility ratio } & 2005 & 0.1526 & 0.0271 & 0.0690 & 0.2587 & \multirow{3}{*}{ [1] } \\
\hline & 2004 & 0.1487 & 0.0269 & 0.0821 & 0.2666 & \\
\hline & 2003 & 0.1434 & 0.0272 & 0.0789 & 0.2885 & \\
\hline Premium (yen) & $2003-05$ & 3,178 & 557 & 1,800 & 5,942 & {$[2]$} \\
\hline \multirow{2}{*}{$\begin{array}{l}\text { FSF loans (against } \\
\text { accumulated } \\
\text { revenues) }\end{array}$} & 2005 & 0.008 & 0.027 & 0.000 & 0.223 & \multirow[b]{2}{*}[1]{} \\
\hline & 2004 & 0.004 & 0.019 & 0.000 & 0.233 & \\
\hline \multirow{2}{*}{ Subsidy rates } & 2005 & 0.383 & 0.023 & 0.325 & 0.442 & \multirow{2}{*}[2]{} \\
\hline & 2004 & 0.382 & 0.021 & 0.325 & 0.436 & \\
\hline $\begin{array}{l}\text { Difference in } 1 \\
\text { (Recipient of the } \\
\text { LAT grants) }\end{array}$ & $2005-04$ & -0.014 & 0.119 & -1.000 & 0.000 & {$[3]$} \\
\hline \multirow{2}{*}{$\begin{array}{l}65+\text { per LTCI insti- } \\
\text { tutional capacities }\end{array}$} & 2005 & 0.032 & 0.005 & 0.022 & 0.048 & \multirow{2}{*}[1]{$+[4]$} \\
\hline & 2004 & 0.032 & 0.006 & 0.023 & 0.049 & \\
\hline \multirow{2}{*}{$\begin{array}{l}\text { Population } \\
\text { (person) }\end{array}$} & 2005 & 69,319 & 208,864 & 292 & $3,579,628$ & \multirow{2}{*}[3]{} \\
\hline & 2004 & 68,209 & 203,130 & 302 & $3,426,651$ & \\
\hline \multirow{2}{*}{$\begin{array}{l}\text { Aged } 65+/ \\
\text { population }\end{array}$} & 2005 & 0.248 & 0.077 & 0.044 & 0.597 & \multirow{2}{*}[1]{$+[3]$} \\
\hline & 2004 & 0.236 & 0.067 & 0.045 & 0.631 & \\
\hline \multirow{2}{*}{$\begin{array}{l}\text { Aged } 75+/ \\
\text { Aged } 65+\end{array}$} & 2005 & 0.480 & 0.061 & 0.294 & 0.727 & \multirow{6}{*}[1]{} \\
\hline & 2004 & 0.470 & 0.057 & 0.274 & 0.717 & \\
\hline \multirow{2}{*}{$\begin{array}{l}\text { Poor Aged 65+/ } \\
\text { Aged } 65+\end{array}$} & 2005 & 0.789 & 0.085 & 0.481 & 0.953 & \\
\hline & 2004 & 0.789 & 0.084 & 0.453 & 0.942 & \\
\hline \multirow{2}{*}{$\begin{array}{l}\text { Rich Aged 65+/ } \\
\text { Aged 65+ }\end{array}$} & 2005 & 0.094 & 0.053 & 0.014 & 0.409 & \\
\hline & 2004 & 0.094 & 0.052 & 0.015 & 0.437 & \\
\hline
\end{tabular}

Note: The sample size is 1,120 .

Sources:

[1] Ministry of Welfare and Labor, Kaoigohoken jigyo hokokusyo [Annual Report on the LTCI Programs].

[2] Data provided by the Ministry of Welfare and Labor.

[3] Ministry of Internal Affairs and Communications, Shichoson kessan jokyo shirabe [Annual Report on Municipal Budgets].

[4] Ministry of Welfare and Labor, Kaigo sabisushisetsu jigyosyo chosa [Survey on the LTC Facilities and Providers].

\subsection{Results}

Table 2 provides the estimation results. As discussed above, we know that the OLS estimates ((a-1) and (a-2)) are not consistent in the presence of endogeneity. Given the results of a test for overidentifying restrictions, both (b-1) and (b-2) pass the test at any standard level of significance (i.e., the test does not reject the joint hypothesis that the model is correctly specified and the instruments are valid). Because the coefficient on 
the lagged dependent variable in (b-2) is highly significant, we argue that the dynamic specification (b-2) is the most appropriate among the four candidate specifications.

Table 2. Estimation Results

\begin{tabular}{|c|c|c|c|c|}
\hline & \multicolumn{2}{|c|}{ (a) OLS } & \multicolumn{2}{|c|}{ (b) Optimal IV (GMM) } \\
\hline & (a-1) Static & (a-2) Dynamic & (b-1) Static & (b-2) Dynamic \\
\hline Drift & $\begin{array}{l}0.649 * * * * \\
(0.124)\end{array}$ & $\begin{array}{l}0.596 \text { **** } \\
(0.126)\end{array}$ & $\begin{array}{l}0.513 * * * * \\
(0.129)\end{array}$ & $\begin{array}{l}0.260 * \\
(0.155)\end{array}$ \\
\hline$\Delta \ln ($ Premiums $)$ & $\begin{array}{l}-0.078 * * * * \\
(0.015)\end{array}$ & $\begin{array}{l}-0.072 * * * * \\
(0.016)\end{array}$ & $\begin{array}{l}-0.061 * * * * \\
(0.016)\end{array}$ & $\begin{array}{c}-0.031 * \\
(0.019)\end{array}$ \\
\hline$\Delta \mathrm{FSF}$ loans & $\begin{array}{l}-0.080 \\
(0.067)\end{array}$ & $\begin{array}{l}-0.079 \\
(0.066)\end{array}$ & $\begin{array}{l}-1.012 * * * \\
(0.431)\end{array}$ & $\begin{array}{c}-0.824 * * \\
(0.370)\end{array}$ \\
\hline$\Delta$ Subsidy rate & $\begin{array}{l}-1.226 \\
(1.212)\end{array}$ & $\begin{array}{l}-1.368 \\
(1.222)\end{array}$ & $\begin{array}{l}-1.050 \\
(1.211)\end{array}$ & $\begin{array}{l}-1.718 \\
(1.314)\end{array}$ \\
\hline$\Delta \mathrm{LAT}$ grants & $\begin{array}{l}-0.002 \\
(0.008)\end{array}$ & $\begin{array}{l}-0.003 \\
(0.008)\end{array}$ & $\begin{array}{c}0.004 \\
(0.009)\end{array}$ & $\begin{array}{l}-0.003 \\
(0.011)\end{array}$ \\
\hline$\Delta \ln ($ Undercapacity) & $\begin{array}{l}-0.034 \\
(0.077)\end{array}$ & $\begin{array}{l}-0.033 \\
(0.077)\end{array}$ & $\begin{array}{c}0.014 \\
(0.080)\end{array}$ & $\begin{array}{l}-0.030 \\
(0.077)\end{array}$ \\
\hline$\Delta \ln (65+/$ Population $)$ & $\begin{array}{c}0.002 \\
(0.126)\end{array}$ & $\begin{array}{l}-0.007 \\
(0.127)\end{array}$ & $\begin{array}{c}0.101 \\
(0.129)\end{array}$ & $\begin{array}{l}-0.032 \\
(0.142)\end{array}$ \\
\hline$\Delta \ln (75+/ 65+)$ & $\begin{array}{l}0.451 * * * * \\
(0.172)\end{array}$ & $\begin{array}{l}0.441 \text { *** } \\
(0.183)\end{array}$ & $\begin{array}{l}0.440 * * * * \\
(0.167)\end{array}$ & $\begin{array}{l}0.334 * \\
(0.192)\end{array}$ \\
\hline$\Delta \ln ($ Poor65+/65+) & $\begin{array}{c}0.098 \\
(0.136)\end{array}$ & $\begin{array}{c}0.096 \\
(0.132)\end{array}$ & $\begin{array}{c}0.077 \\
(0.123)\end{array}$ & $\begin{array}{r}0.028 \\
(0.093)\end{array}$ \\
\hline$\Delta \ln ($ Rich $65+/ 65+)$ & $\begin{array}{c}0.005 \\
(0.013)\end{array}$ & $\begin{array}{c}0.003 \\
(0.013)\end{array}$ & $\begin{array}{c}0.009 \\
(0.014)\end{array}$ & $\begin{array}{c}0.003 \\
(0.015)\end{array}$ \\
\hline$\Delta \ln ($ Population $)$ & $\begin{array}{l}-0.064 \\
(0.112)\end{array}$ & $\begin{array}{l}-0.074 \\
(0.113)\end{array}$ & $\begin{array}{c}0.046 \\
(0.116)\end{array}$ & $\begin{array}{l}-0.083 \\
(0.128)\end{array}$ \\
\hline $\begin{array}{l}\text { Lagged dependent } \\
\text { variable }\end{array}$ & & $\begin{array}{l}0.081 * * \\
(0.040)\end{array}$ & & $\begin{array}{l}0.480 * * * * \\
(0.138)\end{array}$ \\
\hline Sample size & 1,120 & 1,120 & 1,120 & 1,120 \\
\hline Degrees of freedom & 1,109 & 1,108 & 1,109 & 1,108 \\
\hline Uncentered $R^{2}$ & 0.291 & 0.296 & & \\
\hline Centered $R^{2}$ & 0.084 & 0.090 & & \\
\hline Adjusted $R^{2}$ & 0.076 & 0.081 & & \\
\hline $\begin{array}{l}\text { Tests for overidentif } \\
\text { restrictions }\end{array}$ & & & & \\
\hline Chi-squared & & & 7.224 & 14.298 \\
\hline$P$-value & & & 0.205 & 0.353 \\
\hline
\end{tabular}

Note: Asterisks $* * * *, * * *, * *$ and $*$ indicate statistical significance at the $0.01,0.025,0.05$ and 0.10 levels, respectively. 
Premiums Premiums are shown to exert statistically significant negative effects on the eligibility ratio in all cases, although less emphatically for (b-2). This result substantiates the proposition first argued by Ando (2007) that municipalities may reduce the eligibility ratio when premiums are high, possibly to avoid even higher premium levels in the next program management period.

FSF loans The coefficients on the accumulated FSF loans show negative signs in all cases but are not statistically significant for the two OLS cases ((a-1) and (a-2)). In contrast, the two GMM estimates ((b-1) and (b-2)) display statistical significance. Because (b-2) is considered to be the most valid estimation, we argue that municipalities with more borrowing from the FSF tend to reduce the eligibility ratio, probably again in the hope of avoiding future hikes in their premiums. This, with a more valid method and disaggregated data, confirms the findings in Shimizutani and Inakura (2006) and contrasts with Ando (2007).

Subsidies from upper levels of government The central subsidies are found to affect the eligibility ratio negatively. This is rather puzzling, as we hypothesized that fiscal stringency leads to a smaller eligibility ratio. However, the most valid case (b-2) exhibits no sign of statistical significance. We could then argue that the subsidies from upper levels of government do not exert any significant effect on the eligibility ratio. Likewise, the LAT recipient status does not statistically affect the ratio. More particularly, its effects are virtually zero in all four cases. This may be due to small variation in the data, because the number of status changes occurring between 2004 and 2005 is quite small $^{13}$ (see Table 1). While the estimates for the LAT may need to be improved, these results imply that transfers from upper government do not affect eligibility certification.

Undercapacity of LTCI facilities As argued, the degree of undercapacity in LTCI facilities might put downward pressures on the eligibility ratio. While the estimates are negative in all six cases, none shows statistical significance.

Population The effects of population are insignificant at any conventional level of statistical significance. We have argued that population may be associated with the market size of long-term care services. Our result implies that market size does not affect the eligibility ratio.

Characteristics of the elderly While the proportion of the elderly (defined as those aged 65 years and over) among the total population does not show any statistically significant effects, the share of those aged 75 years and over among the elderly has positive effects that are statistically significant in all cases. This probably reflects the fact that long-term care needs increase as people become very old. However, the other variables that characterize the elderly population do not exhibit any statistical significance.

Lagged dependent variable The dynamic effects are all statistically significant when considered ((a-2), (b-2)), demonstrating dynamic dependence. It may be worth noting that including the lagged dependent makes the fiscal variable less significant.

\footnotetext{
${ }^{13}$ Note also that because $d_{i t}$ is a binary variable indicating the receipt of LAT, $\Delta d_{i t}$ takes on values of 0 with no status change, 1 with a change from nonrecipient to recipient and -1 with a change from recipient to nonrecipient.
} 
Drift The constant terms (drifts) are positive and statistically significant. This reflects the increase in the eligibility ratio from 2004 to 2005, even after all the explanatory variables employed in the estimation are controlled.

\section{Concluding Remarks}

Prior to the introduction of the LTCI, different standards applied among localities because most long-term care services had been independently developed by local governments in the absence of a comprehensive national framework. Upon application by the elderly, local governments determined their eligibility, the types and volumes of services to be provided and, if applicable, the fees to be paid. Occasionally, the identically needy were treated differently, even within a given locality. The delivery process tended to adhere to some fixed regulations but sometimes yielded to pressures from local politicians to provide services to favored constituents (Ikegami, 2007). While both home and institutional care were available, long-term care was provided as a combination of medical and social services. Institutional care was more expensive than comparable medical services, as health insurance fully covers hotel costs for the latter. In fact, most long-term care was through "medical" services at private hospitals that effectively provide "institutional" care.

The introduction of the LTCI in 2000 was indeed an improvement over the existing regime. However, the current study has indicated that there is room for further improvement. We have found that municipalities in stringent fiscal climates tend to reduce the number of persons eligible for LTCI benefits, almost certainly in the hope of containing benefit expenditures. This would not be a serious problem if financial assistance from the upper levels of government counteracted this adverse effect, because there are layers of intergovernmental transfers in the current LTCI system. Nonetheless, we have also shown that the effects of transfers are almost negligible and statistically insignificant. This would seem to be odd at first glance, because on average 81 percent of standard LTCI benefits are financed through some type of revenue sharing scheme. ${ }^{14}$

Nonetheless, municipalities may still want to control the eligibility ratio to contain expanding LTCI benefits because there are always expenditures to be financed by their own Category I premiums. If there is an unexpected increase in LTCI benefits, some portion will have to be financed by an increase in premiums in the future because compensation from upper levels of government is still only partial. We could use this finding to argue that the system of LTCI used in Japan is equipped with an effective gatekeeping mechanism. However, at the same time, we could also argue that the system compromises horizontal equity in favor of gatekeeping. That is, the identically needy may become eligible in one location and not in another, even in a nationally integrated system of long-term care provision.

\footnotetext{
${ }^{14}$ Because LAT grants in municipalities supplement intramunicipal transfers, the tax-financed part that constitutes $50 \%$ of total revenue arrives as revenue sharing of some form. Moreover, $31 \%$ of total revenues come as FPFG financed from Category II premiums nationally pooled at the SIMFPF.
} 


\section{References}

Ando, M., 2007, Kaigohokenja wa kaigokyufu wo yokuseishiteiruka: Hokenja deta niyoru jisshobunseki [Do the Insurers Suppress the Long-Term Care Insurance Benefits? An Empirical Analysis with Municipal Data], Master's Thesis Presented to the Department of Social Science, Hitotsubashi University.

Board of Audit of Japan, 2006, Outline of Audit Results: FY2005 Audit Report (available at http://www.jbaudit.go.jp/engl/index.htm).

Campbell, J.C. and N. Ikegami, 2000, "Long-term Care Insurance Comes to Japan", Health Affairs 19(3), 26-39.

Endo, H. and A. Yoshida, 2001, "Kazoku no dokyo-bekkyo sentaku to homon kaigo sabisu juyo [The Choice of Household Separation and Home-care Demands]", Kikan Syakai Hosyo Kenkyu [Quarterly of Social Security Research] 37(3), 281296.

Glendinning, C., B. Davies, L. Pickard and A. Comas-Herrera, 2004, Funding Longterm Care for Older People: Lessons from Other Countries (York: Joseph Rowntree Foundation).

Hirota, K., 2006, "Shichoson-gappei ni okeru kyogikai secchi no koka to seisaku hyoka [An Evaluation of Municipal Amalgamations in Japan]", Paper presented at the 10th Annual Meeting of the Japan Public Choice Society, Kyoto University, July $1-2,2006$.

Ikegami, N., 2007, "Rationale, Design and Sustainability of Long-term Care Insurance in Japan: In retrospect”, Social Policy and Society 6(3), 423-434.

Mitchell, O.S., J. Piggott and S. Shimizutani, 2004, “Aged-care Support in Japan: Perspectives and Challenges”, NBER Working Paper Series, No. 10882, National Bureau of Economic Research.

Muiser, J. and G. Carrin, 2007, "Financing Long-term Care Programmes in Health Systems, With a Situation Assessment in Selected High-, Middle- and Low-income Countries", Discussion Paper No. 6, World Health Organization.

Shimizutani, S. and N. Inakura, 2006, "Koteki kaigo hoken seido no unyo to hokensya zaisei [The Management of the Long-Term Care Insurance Program and its Financing]", Kaikei Kensain Kenkyu [Board of Audit Review], 34, 83-95.

Wooldridge, J.M., 2002, Econometric Analysis of Cross Section and Panel Data (Cambridge, MA: The MIT Press). 